\title{
2-Methoxycycloocta-1,5-dienyl platinum complexes as precursors for platinum nanoparticles
}

\author{
NINAD GHAVALE, SANDIP DEY, VIMAL K JAIN* and R TEWARI ${ }^{\dagger}$ \\ Chemistry Division, ${ }^{\dagger}$ Materials Science Division, Bhabha Atomic Research Centre, Mumbai 400 085, India
}

MS received 3 July 2008

\begin{abstract}
Thermolysis of $\left[\mathrm{Pt}_{2}(\mu-\mathrm{OR})_{2}\left(\mathrm{C}_{8} \mathrm{H}_{12} \mathrm{OMe}\right)_{2}\right](\mathrm{R}=\mathrm{Me}$ or $\mathrm{Ac})$ in hexadecylamine (HDA) at $210^{\circ} \mathrm{C}$ under argon atmosphere gave platinum nanoparticles which were characterized by XRD, EDAX and TEM analysis. Both spherical $(\sim 10 \mathrm{~nm})$ and rod-like $(\sim 19 \mathrm{~nm}$ length with aspect ratio of 2.3$)$ face centred cubic $(f c c)$ platinum metal nanoparticles could be isolated. The thermogravimetric analyses of these complexes revealed that they undergo a single step decomposition leading to the formation of platinum metal powder.
\end{abstract}

Keywords. Platinum complexes; pyrolysis; platinum nanoparticles; XRD; TEM.

\section{Introduction}

Noble-metal nanoparticles have attracted considerable attention during the last 15 years or so due to their applications in catalysis, electronics and biology (Eustis and Al-Sayed 2006; Astruc 2008). Palladium and platinum nanoparticles are widely used for hydrogenation (Mandal et al 2002; Wilson et al 2006; Ganesan et al 2007) and $\mathrm{C}-\mathrm{C}$ coupling (Gaikwad et al 2007; Gallon et al 2007; Kovala-Demertzi et al 2008; Yang et al 2008) reactions, oxidation of alcohols (Wang et al 2007) and hydrogen absorption (Kobayashi et al 2008). Platinum nanoparticles are prepared by different methods like sono-chemical (Fujimoto et al 2001), radiolytic (Belapurkar et al 2001) and predominantly by chemical reduction of either $\mathrm{PtCl}_{2}$ or $\mathrm{H}_{2} \mathrm{PtCl}_{6}$ in the presence of a suitable capping agent. A variety of reducing agents, such as hydrogen (Yamada et al 2005; Wang and Toshima 1997), $\mathrm{NaBH}_{4}$ (van Rheenen et al 1983; Perez et al 1999), hydrazine (Solla-Gullon et al 2000) and potassium bitartarate (Tan et al 2003) have been successfully employed for the preparation of platinum nanoparticles in different shapes (Ahmadi et al 1996; Bi and $\mathrm{Lu} 2008$ ).

Palladium and platinum chlorides, e.g. $\mathrm{PdCl}_{2}$ in Wacker process and $\mathrm{H}_{2} \mathrm{PtCl}_{6}$ in hydrosilylation, are widely used in organic transformations involving olefins (Speier et al 1957; Smidt et al 1962; Speier 1979). Although identity of active catalytic species in these reactions often remain elusive, a metal(0), usually metal nanoparticles species, is believed to be an active catalyst. For instance hydrosilylation of olefins by chloroplatinic acid requires induction

*Author for correspondence (jainvk@barc.gov.in) period during which an active catalytic species, finely divided platinum(0), forms. Arguably platinum olefin complexes may, therefore, serve as precursors for the preparation of platinum nanoparticles, although organometallic platinum complexes have been used for deposition of thin films on a variety of substrates (Hierso et al 1998). Thus to evaluate suitability of platinum olefin complexes for the preparation of platinum nanoparticles we have chosen two well characterized platinum complexes, $\left[\mathrm{Pt}_{2}(\mu \text {-OR })_{2}\left(\mathrm{C}_{8} \mathrm{H}_{12} \mathrm{OMe}\right)_{2}\right](\mathrm{R}=\mathrm{Me}, \mathrm{Ac})$, reported in the literature (Giordano and Vitagliano 1981; Goel et al 1981; Goel and Vanderveer 1984) for the present investigation. The results of this work are presented herein.

\section{Experimental}

\subsection{Materials}

The complexes, $\left[\mathrm{Pt}_{2}(\mu \text {-OR })_{2}\left(\mathrm{C}_{8} \mathrm{H}_{12} \mathrm{OMe}\right)_{2}\right](\mathrm{R}=\mathrm{Me}, \mathrm{Ac})$, were prepared according to literature methods (Giordano and Vitagliano 1981; Goel et al 1981; Goel and Vanderveer 1984), purified by recrystallization and characterized by elemental analysis and ${ }^{1} \mathrm{H}$ NMR spectral data. Solvo-thermal decomposition was carried out in a threenecked round bottom flask under an argon atmosphere.

\subsection{Instruments}

TG curves were obtained at a heating rate of $10^{\circ} \mathrm{C} \mathrm{min}^{-1}$ under flowing argon on a Setaram 92-16-18 instrument. EDAX and SEM were recorded on a Tescan Vega 2300T/40 instrument. Powder XRD patterns were recorded on a Philips PW1820 using $\mathrm{Cu}-\mathrm{K}_{\alpha}$ radiation. A JEOL- 
2
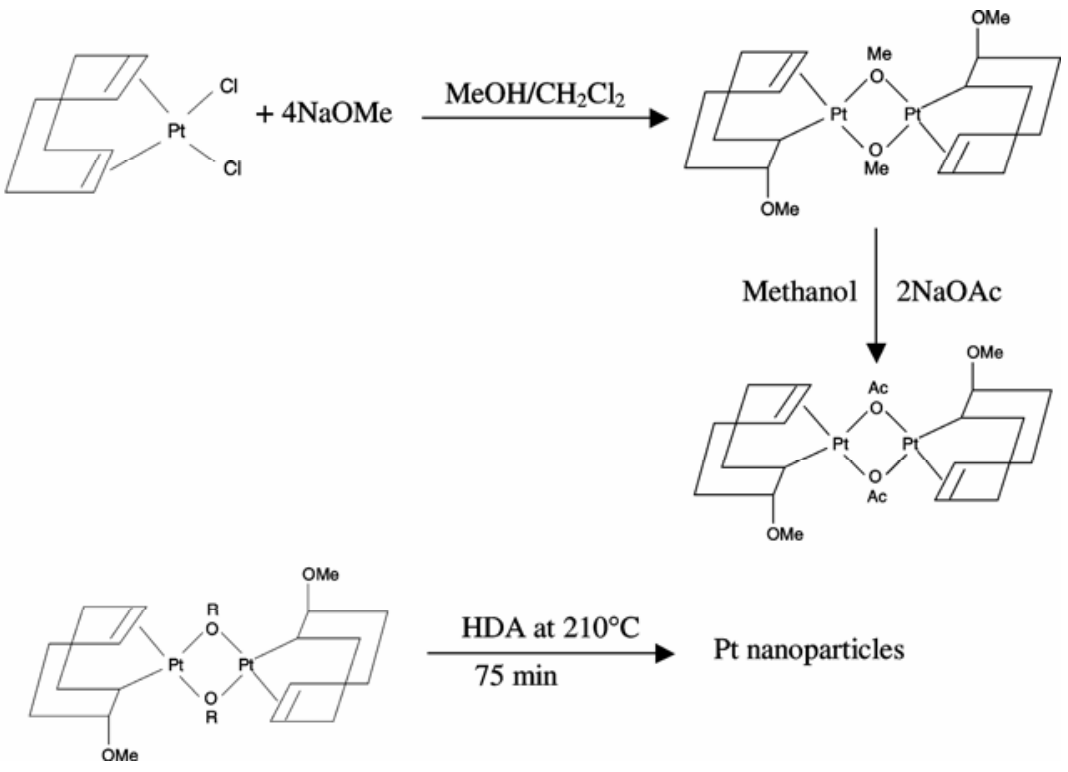

Pt nanoparticles

Scheme 1.

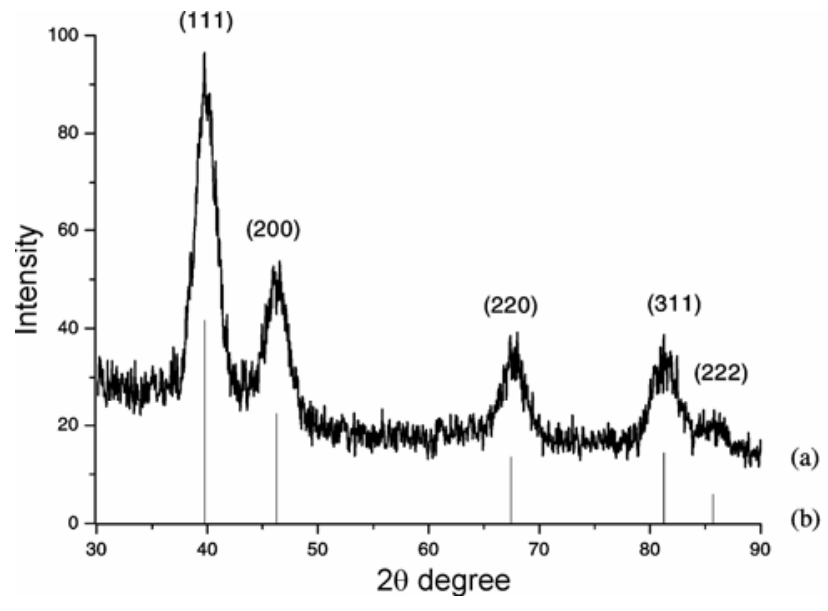

Figure 1. (a) Powder XRD pattern of the residue obtained after decomposition of $\left[\mathrm{Pt}_{2}(\mu \text {-OMe })_{2}\left(\mathrm{C}_{8} \mathrm{H}_{12} \mathrm{OMe}\right)_{2}\right]$ in HDA at $210^{\circ} \mathrm{C}$. (b) Powder Diffraction File No. 04-0802 compiled by JCPDS-ICDD, International Centre for Diffraction Data USA, 1990.

200FX transmission electron microscope operating at accelerating voltages up to $200 \mathrm{kV}$ was used for TEM studies. The samples for TEM and SAED were prepared by placing a drop of sample dispersed in acetone on a carbon-coated copper grid.

\subsection{Preparation of Pt nanoparticles}

(a) A mixture of $\left[\mathrm{Pt}_{2}(\mu-\mathrm{OMe})_{2}\left(\mathrm{C}_{8} \mathrm{H}_{12} \mathrm{OMe}\right)_{2}\right](59 \mathrm{mg}$, $0.08 \mathrm{mmol})$ and HDA $(2.5 \mathrm{~g})$ was taken in a $100 \mathrm{~mL}$ three-necked round-bottom flask and degassed at $90^{\circ} \mathrm{C}$ under vacuum and stirring for $30 \mathrm{~min}$. The reaction flask was filled with argon and the temperature was raised to $150^{\circ} \mathrm{C}$ and maintained for $15 \mathrm{~min}$ whereupon colour changed from pale yellow to yellowish-brown indicating decomposition of the precursor. The reaction temperature was further raised to $210^{\circ} \mathrm{C}$ and maintained for $30 \mathrm{~min}$ during which a black residue was formed. The reaction mixture was then cooled to $60^{\circ} \mathrm{C}$ and $10 \mathrm{~cm}^{3}$ of toluene was added. A black precipitate was obtained by adding methanol which was then separated by centrifugation, washed with methanol and dried. Similarly, decomposition of $\left[\mathrm{Pt}_{2}(\mu-\mathrm{OAc})_{2}\left(\mathrm{C}_{8} \mathrm{H}_{12} \mathrm{OMe}\right)_{2}\right]$ in $\mathrm{HDA}$ at $210^{\circ} \mathrm{C}$ also yielded platinum nanoparticles.

(b) A weighed amount of $\left[\mathrm{Pt}_{2}(\mu-\mathrm{OMe})_{2}\left(\mathrm{C}_{8} \mathrm{H}_{12} \mathrm{OMe}\right)_{2}\right]$ (70 mg, $0.09 \mathrm{mmol}$ ) was taken in a quartz boat and heated in a furnace at $250^{\circ} \mathrm{C}$ for $3 \mathrm{~h}$ under flowing argon. The residue obtained was washed with benzene and hexane and dried under vacuum $(41 \mathrm{mg}, 58 \%)$.

\section{Results and discussion}

The complexes, $\left[\mathrm{Pt}_{2}(\mu \text {-OR })_{2}\left(\mathrm{C}_{8} \mathrm{H}_{12} \mathrm{OMe}\right)_{2}\right](\mathrm{R}=\mathrm{Me}, \mathrm{Ac})$, were prepared according to the reaction routes shown in scheme 1 and were used after recrystallization (Giordano and Vitagliano 1981; Goel et al 1981; Goel and Vanderveer 1984). Thermogravimetric analyses of $\left[\mathrm{Pt}_{2}(\mu\right.$ $\left.\mathrm{OR})_{2}\left(\mathrm{C}_{8} \mathrm{H}_{12} \mathrm{OMe}\right)_{2}\right](\mathrm{R}=\mathrm{Me}, \mathrm{Ac})$ complexes were carried out. The TG curves of these complexes showed a single step of decomposition with an onset temperature of $149^{\circ} \mathrm{C}$ for $\left[\mathrm{Pt}_{2}(\mu-\mathrm{OMe})_{2}\left(\mathrm{C}_{8} \mathrm{H}_{12} \mathrm{OMe}\right)_{2}\right]$ and $144^{\circ} \mathrm{C}$ for $\left[\mathrm{Pt}_{2}(\mu-\mathrm{OAc})_{2}\left(\mathrm{C}_{8} \mathrm{H}_{12} \mathrm{OMe}\right)_{2}\right]$ complexes. The TG data indicates that acetato-bridged complex is more labile than the methoxy bridged derivative. The solvothermal decomposition of both the complexes in coordinating solvents 
such as HDA (hexadecylamine, bp: $330^{\circ} \mathrm{C}$ ) at $210^{\circ} \mathrm{C}$ led to the formation of platinum nanoparticles as inferred from powder XRD patterns (figure 1) (JCPDS file no. 04-

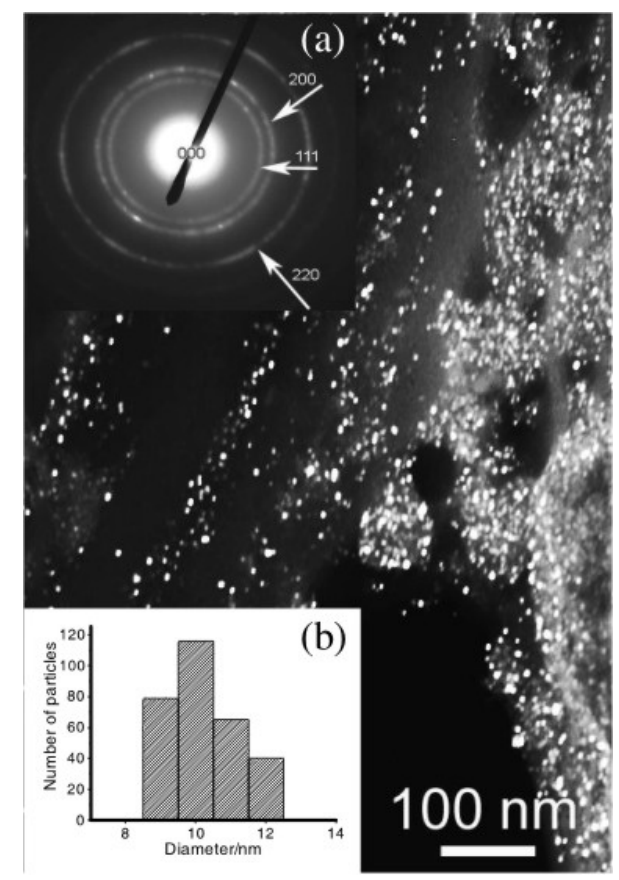

Figure 2. TEM picture of residue obtained after decomposition of $\left[\mathrm{Pt}_{2}(\mu-\mathrm{OMe})_{2}\left(\mathrm{C}_{8} \mathrm{H}_{12} \mathrm{OMe}\right)_{2}\right]$ in $\mathrm{HDA}$ at $210^{\circ} \mathrm{C}$; insets show (a) SAED pattern and (b) size distribution.

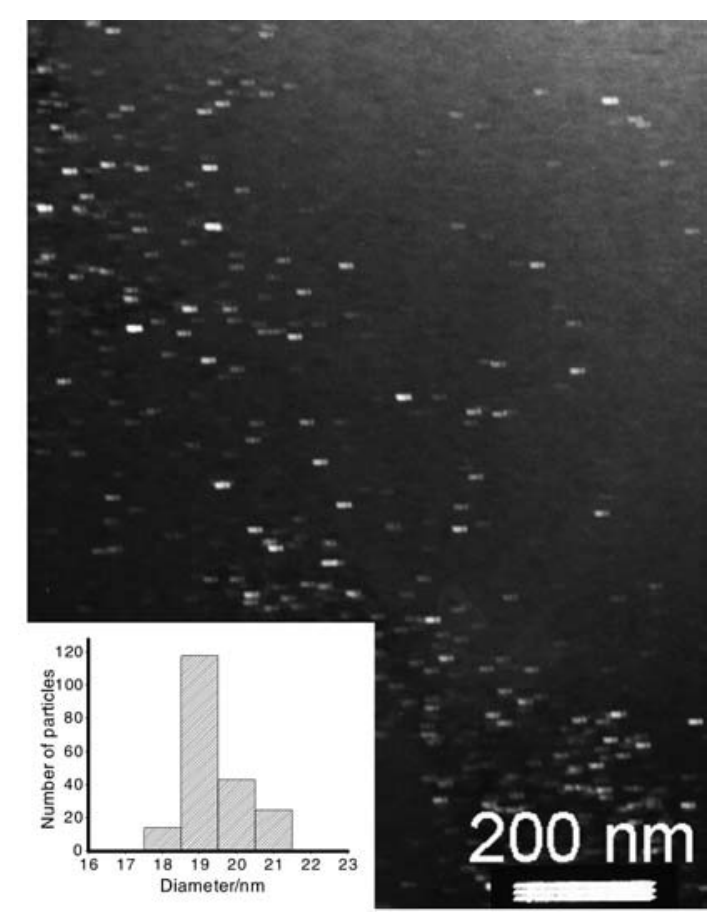

Figure 3. TEM picture of residue obtained after decomposition of $\left[\mathrm{Pt}_{2}(\mu-\mathrm{OAc})_{2}\left(\mathrm{C}_{8} \mathrm{H}_{12} \mathrm{OMe}\right)_{2}\right]$ in $\mathrm{HDA}$ at $210^{\circ} \mathrm{C}$; inset shows size distribution.
$0802)$ of the residue. The complex $\left[\mathrm{Pt}_{2}(\mu-\mathrm{OMe})_{2}\right.$ $\left.\left(\mathrm{C}_{8} \mathrm{H}_{12} \mathrm{OMe}\right)_{2}\right]$ on pyrolysis in a furnace at $250^{\circ} \mathrm{C}$ gave platinum metal powder as inferred from powder XRD patterns of the residue.

The particle sizes calculated from Scherrer formula for the samples prepared by thermolysis in $\mathrm{HDA}$ at $210^{\circ} \mathrm{C}$ were $3.6 \pm 0.6 \mathrm{~nm}$ (from $\left.\left[\mathrm{Pt}_{2}(\mu-\mathrm{OMe})_{2}\left(\mathrm{C}_{8} \mathrm{H}_{12} \mathrm{OMe}\right)_{2}\right]\right)$ and $3 \pm 0.6 \mathrm{~nm}$ (from $\left.\left[\mathrm{Pt}_{2}(\mu-\mathrm{OAc})_{2}\left(\mathrm{C}_{8} \mathrm{H}_{12} \mathrm{OMe}\right)_{2}\right]\right)$. The TEM images of the former (methoxy bridged complex) showed that the particles are in spherical shape with average diameter of $\sim 10 \mathrm{~nm}$ (figure 2) while in the latter (acetatebridged complex), they were rod-like with aspect ratio of 2.3 and average diameter of $\sim 19 \mathrm{~nm}$ (figure 3 ). The mismatch between the sizes estimated by XRD and obtained by TEM is because particles size does not determine linewidth directly in XRD. The SAED patterns displaying concentric rings (inset of figure 2a) corresponding to the lattice planes (111), (200) and (220) are consistent with the $f c c$ phase of the platinum nanoparticles. The size distribution of particles (from $\left[\mathrm{Pt}_{2}(\mu-\mathrm{OMe})_{2}\left(\mathrm{C}_{8} \mathrm{H}_{12} \mathrm{OMe}\right)_{2}\right]$ ) was measured by counting 300 particles. The average size of particles was $10.5 \pm 0.5 \mathrm{~nm}$, with sizes ranging from 9-12 nm (inset of figure 2b). Also the size distribution of rod-shaped particles (from $\left[\mathrm{Pt}_{2}(\mu-\mathrm{OAc})_{2}\left(\mathrm{C}_{8} \mathrm{H}_{12} \mathrm{OMe}\right)_{2}\right]$ ) was measured by counting 200 particles. The average size of particles was $19.5 \pm 0.5 \mathrm{~nm}$ in length, with sizes ranging from $18-21 \mathrm{~nm}$ (inset of figure 3 ).

\section{Acknowledgements}

We are thankful to Mr Suresh Chopade for providing TG analyses. One of the authors (NG) is thankful to DAE for the award of a senior research fellowship.

\section{References}

Ahmadi T S, Wang Z L, Green T C, Henglein A and El-Sayed M A 1996 Science 2721924

Astruc D 2008 Nanoparticles and catalysis (Weinheim: Wiley$\mathrm{VCH})$

Belapurkar A D, Kapoor S, Kulshreshtha S K and Mittal J P 2001 Mater. Res. Bull. 36145

Bi Y and Lu G 2008 Chem. Mater. 201224

Eustis S and Al-Sayed M A 2006 Chem. Soc. Rev. 35209

Fujimoto T, Terauchi S, Umehara H, Kojima I and Henderson W 2001 Chem. Mater. 131057

Gaikwad A V, Holuigue A, Thathagar M B, Elshof J E and Rothenberg G 2007 Chem. Eur. J. 136908

Gallon B J, Kojima R W, Kaner R B and Diaconescu P L 2007 Angew Chem. Int. Ed. 467251

Ganesan M, Freemantle R G and Obare S O 2007 Chem. Mater. 193464

Giordano F and Vitagliano A 1981 Inorg. Chem. 20633

Goel A B and Vanderveer D 1984 Inorg. Chim. Acta 87 L19

Goel A B, Goel S and Vanderveer D G 1981 Inorg. Chim. Acta 54 L169 
Hierso J C, Feurer R and Kalck P 1998 Coord. Chem. Rev. 178-180 1811

Kobayashi H, Yamauchi M, Kitagawa H, Kubota Y, Kato K and Takata M 2008 J. Am. Chem. Soc. 1301818

Kovala-Demertzi D, Kourkoumelis N, Derlat K, Michalak J, Andreadaki F J and Kostas I D 2008 Inorg. Chim. Acta 361 1562

Mandal S, Selvakannan P R, Roy D, Chaudhari R V and Sastry M 2002 Chem. Commun. 3002

Perez H, Pradeau J P, Albouy P A and Perez-Omil J 1999 Chem. Mater. 113460

Smidt J, Hafner W, Jira R, Sieber R, Sedlmeier J and Sabel A 1962 Angew Chem. Int. Ed. 180

Solla-Gullon J, Montiel J V, Aldaz A and Clavilier J $2000 \mathrm{~J}$. Electroanal. Chem. 49169
Speier J 1979 Adv. Organomet. Chem. 17407

Speier J L, Webster J A and Barnes G H 1957 J. Am. Chem. Soc. 79974

Tan Y, Dai X, Li Y and Zhu D 2003 J. Mater. Chem. 131069

van Rheenen P, McKelvy M, Marzke R and Glaunsinger W S 1983 Inorg. Synth. 24238

Wang T, Xiao C X, Yan L, Xu L, Luo J, Shou H, Kou Y and Liu H 2007 Chem. Commun. 4375

Wang Y and Toshima N 1997 J. Phys. Chem. B101 5301

Wilson O M, Knecht M R, Garcia-Martinez J C and Crooks R M 2006 J. Am. Chem. Soc. 1284510

Yamada M, Kon S and Miyake M 2005 Chem. Lett. 34 1050

Yang X, Fei Z, Zhao D, Ang W H, Li Y and Dyson P J 2008 Inorg. Chem. 473292 